\title{
Antiviral treatment in congenital HCMV infection: The six-year experience of a single neonatal center in Poland
}

\author{
Dominika Jedlińska-Pijanowska ${ }^{1, A-F}$, Justyna Czech-Kowalska ${ }^{1, A-F}$, Magdalena Kłodzińska ${ }^{1, B-F}$, Aleksandra Pietrzyk ${ }^{1, B-F}$, \\ Eliza Michalska ${ }^{1, B-F}$, Kinga Gradowska ${ }^{1, B-F}$, Anna Dobrzańska ${ }^{1, A-C, E, F}$, Beata Kasztelewicz ${ }^{2, B-F}$, Dariusz Gruszfeld ${ }^{1, A-C, E, F}$ \\ ${ }^{1}$ Neonatal Intensive Care Unit, The Children's Memorial Health Institute, Warsaw, Poland \\ 2 Department of Clinical Microbiology and Immunology, The Children's Memorial Health Institute, Warsaw, Poland \\ A - research concept and design; $\mathrm{B}$ - collection and/or assembly of data; $\mathrm{C}$ - data analysis and interpretation; \\ $D$ - writing the article; $E$ - critical revision of the article; $F$ - final approval of the article
}

Address for correspondence

Justyna Czech-Kowalska

E-mail: j.kowalska@ipczd.pl

Funding sources

None declared

Conflict of interest

None declared

Received on February 5, 2020

Reviewed on May 13, 2020

Accepted on July 16, 2020

Published online on 0ctober 14, 2020

Cite as

Jedlińska-Pijanowska D, Czech-Kowalska J, Kłodzińska M, et al. Antiviral treatment in congenital HCMV infection: The six-year experience of a single neonatal center in Poland. Adv Clin Exp Med. 2020;29(10):1161-1167. doi:10.17219/acem/125427

DOI

10.17219/acem/125427

\section{Copyright}

Copyright by Author(s)

This is an article distributed under the terms of the

Creative Commons Attribution 3.0 Unported (CC BY 3.0)

(https://creativecommons.org/licenses/by/3.0/)

\begin{abstract}
Background. Antiviral treatment is recommended for symptomatic newborns with congenital cytomegalovirus infection (cCMV).

Objectives. To compare 2 treatment methods in neonates with cCMV - ganciclovir-based therapy (intravenous ganciclovir (GCV) or sequential GCV + valganciclovir (VGCV) therapy) with oral VGCV-based therapy - in Polish neonates.
\end{abstract}

Material and methods. A total of 98 symptomatic infants with cCMV (positive HCMV DNA in urine $\leq 21^{\text {st }}$ day of life) hospitalized in the neonatal intensive care unit (NICU) between 2012 and 2017 were enrolled. Clinical characteristics, the viral load in blood and urine, hematological and biochemical tests, neuroimaging results, and the length of hospitalization were compared between the study groups at baseline and at the $2^{\text {nd }}$ hospitalization.

Results. In 2012, GCV was used in 57\% of the cases, sequential therapy in 33\% and VGCV in 10\%. In 2017, VGCV monotherapy was used in $83 \%$ of the infants treated. Valganciclovir treatment allowed the length of hospitalization to be shortened over 2.5 times during the six-year observation period. Infants treated intravenously had lower birth weights and head circumferences, and more frequently presented splenomegaly, petechiae, thrombocytopenia, and hepatitis. The baseline viral load in the blood and urine were similar in both groups, but at follow-up visits 4-6 weeks later, a viral load about 70 times lower was observed in the blood of the VGCV-based group (1029 viral copies/mL compared to 72,188 viral copies/mL in the GCV-based group; $p=0.04)$. The prevalence of neutropenia was similar in both groups at the follow-up visits.

Conclusions. Valganciclovir became the first line of antiviral therapy in cCMV in the study population. Compared to GCV-based therapy, VGCV monotherapy allowed shorter hospital stays and reduced the viral load in blood due to continuing treatment at home. Valganciclovir monotherapy did not provoke more side effects such as neutropenia. Intravenous GCV is still suitable for patients with severe disseminated disease, born prematurely, with low birth weights, or not tolerating enteral feeding. In those infants, the sequential therapy seems to be optimal.

Key words: congenital, human cytomegalovirus, ganciclovir, valganciclovir, cytomegaly 


\section{Introduction}

Human cytomegalovirus (HCMV), which belongs to the Herpesviridae (HHV-5), is widespread all over the world. It is estimated that $50-80 \%$ of the population is $\mathrm{HCMV}$-seropositive in developed countries, and up to $95-100 \%$ in developing countries. ${ }^{1,2}$ Congenital cytomegalovirus infection (cCMV) is the most common intrauterine infection. ${ }^{2,3}$ In the USA, it affects about $0.5-1 \%$ of newborns, which means as many as 40,000 infected newborns per year. ${ }^{4,5}$ However, only $10-15 \%$ of infected newborns are symptomatic at birth. ${ }^{6,7}$ Central nervous system (CNS) abnormalities include microcephaly, abnormal neuroimaging (intracerebral calcifications, intra-/paraventricular cysts, ventriculomegaly), sensorineural hearing loss (SNHL), and chorioretinitis. ${ }^{8}$ Hepatobiliary and reticuloendothelial system disorders consist of hepatomegaly, splenomegaly, petechiae, thrombocytopenia, neutropenia, hepatitis, and cholestasis. ${ }^{9}$ Among HCMV-seropositive newborns that are initially asymptomatic, up to $15-25 \%$ will develop late-onset sequelae. The SNHL and neurodevelopmental retardation, including cognitive delays and motor impairments such as cerebral palsy, are the most common long-term outcomes in $\mathrm{CCMV}^{3,5,10}$ Antiviral treatment improves audiological and developmental outcomes. ${ }^{11}$ Two of the 5 drugs approved by the Federal Drug Administration (FDA) for treatment of HCMV - ganciclovir (GCV) and its oral pro-drug valganciclovir (VGCV) - were studied in newborns with cCMV. Initially, antiviral treatment for cCMV consisted of 6 weeks of intravenous therapy with GCV. ${ }^{12}$ Then, it was documented that an oral solution of VGCV provided comparable plasma concentrations of GCV as intravenous GCV. ${ }^{13}$ Finally, randomized clinical trials showed that for infants, 6 months of VGCV therapy was much more beneficial than 6 weeks of GCV, and both treatments were approved by the American Academy of Pediatrics (AAP). ${ }^{9,11,14}$

The aim of the study was to compare 2 treatment methods in neonates with cCMV over time: GCV-based therapy (intravenous GCV or sequential GCV + VGCV therapy) and oral VGCV-based therapy alone.

\section{Material and methods}

Caucasian neonates with symptomatic cCMV on antiviral treatment were recruited for the study at the Neonatal Intensive Care Unit (NICU) of the Children's Memorial Health Institute in Warszawa (Poland). The analyzed data was collected retrospectively between 2012 and 2017. Inclusion criteria for the study were positive real-time polymerase chain reaction (RT-PCR) results for HCMV DNA in urine before or on the $21^{\text {st }}$ day of life, symptomatic infection and antiviral treatment. A symptomatic case was defined by 1 or more CNS abnormalities and/or a minimum of 3 hepatobiliary and reticuloendothelial system disorders. The following definitions of laboratory abnormalities were adopted in the study: elevated direct bilirubin $>1 \mathrm{mg} / \mathrm{dL}$ for cholestasis; elevated levels of aspartate transaminase (ASPAT) $>84 \mathrm{U} / \mathrm{L}$ and/or elevated levels of alanine aminotransferase (ALTAT) $>60 \mathrm{U} / \mathrm{L}$ for hepatitis; thrombocytopenia below $100 \mathrm{G} / \mathrm{L}$; neutropenia below $1000 \mathrm{G} / \mathrm{L}$; positive CMV-immunoglobulin G (IgG) $\geq 6 \mathrm{AU} / \mathrm{mL}$; negative CMV-IgG < $6 \mathrm{AU} / \mathrm{mL}$; positive $\mathrm{HCMV}$-immunoglobulin $\mathrm{M}$ (IgM) $\geq 1 \mathrm{AU} / \mathrm{mL}$; greyzone HCMV-IgM 0.85-0.99 AU/mL; and negative CMV$\operatorname{IgM}<0.85 \mathrm{AU} / \mathrm{mL}$. Exclusion criteria were negative RT-PCR CMV DNA in urine before or on the $21^{\text {st }}$ day of life; a lack of the PCR results before or on the $21^{\text {st }}$ day of life; asymptomatic infection including isolated symptoms such as prematurity or intrauterine growth restriction (IUGR); and congenital malformations. Depending on the type of treatment, 2 groups were distinguished in the study: group 1 - GCV-based therapy (neonates treated only intravenously with GCV and neonates treated sequentially with GCV followed by oral VGCV); and group 2 - VGCV-based therapy (neonates treated only orally). Ganciclovir was scheduled to be administered intravenously at a dose of $6 \mathrm{mg} / \mathrm{kg}$ every $12 \mathrm{~h}$ for 6 weeks during baseline hospitalization. Infants treated intravenously were assessed again 4-6 weeks after the cessation of antiviral therapy. Valganciclovir was administered orally at a dose of $16 \mathrm{mg} / \mathrm{kg}$ every $12 \mathrm{~h}$ during baseline hospitalization, and continued at home and during the follow-up hospitalization. Drug levels were measured during treatment (data not presented). The clinical evaluation, hematological and biochemical tests, serology, qualitative and quantitative RT-PCR for HCMV DNA in blood and urine, and qualitative RT-PCR for HCMV DNA in cerebrospinal fluid (CSF), neuroimaging (ultrasound (US) and magnetic resonance imaging (MRI)), newborn hearing screening tests (otoacoustic emission (OAE)) and ophthalmologic consultations were performed at baseline and in part also at the follow-up visits (about 4-6 weeks after the $1^{\text {st }}$ hospitalization). The HCMV DNA viremia and viruria (viral load) were determined in whole blood and urine samples using RT-PCR and GeneProof Cytomegalovirus PCR Kits (GeneProof, Brno, Czech Republic). The results were expressed as copies per $\mathrm{mL}$ (blood or urine). The qualitative detection of HCMV DNA in CSF was done with RT-PCR using the SYBRGreen I format and a primer set specific for the phosphoprotein pp65(UL83) gene. ${ }^{15}$ The sensitivity of the assay was 250 copies $/ \mathrm{mL}$. The statistical analysis was performed using STATISTICA v. 7.0 for Windows (StatSoft Inc., Tulsa, USA). All data was presented as mean \pm standard deviation (SD) or number (\%). The p-values below 0.05 were considered statistically significant.

The study protocol was approved by the ethics committee on human subjects of the Children's Memorial Health Institute (Warszawa, Poland). We declare compliance with ethical practices in the study. 


\section{Results}

A total of 123 newborns with cCMV were hospitalized in the NICU during the study period. The final analysis was performed in 98 symptomatic newborns offered antiviral therapy. Twenty-five asymptomatic newborns who were not treated were excluded. Among the treated neonates, there were 30 preterm newborns ( 4 neonates $<32$ weeks of gestation). Only 2 preterm newborns had extremely low birth weights (ELBW), 1 newborn had a birth weight appropriate for the gestational age (AGA) and 1 had intrauterine growth restriction (IUGR).

In most cases, antiviral therapy was introduced during the $1^{\text {st }}$ month of life. Ganciclovir was used in 60 participants (group 1) - in 13 cases as a monotherapy (12 cases in 2012) and in 47 participants as sequential therapy. Valganciclovir was used as a monotherapy in 38 neonates (group 2). The characteristics of the study population and treatment groups are presented in Table 1.

The mean duration of intravenous therapy was $24 \pm 10$ days in the entire study population. When GCVbased therapy (group 1) was analyzed in detail, GCV was administered for $34 \pm 9$ days in the monotherapy and $22 \pm 9$ days in sequential therapy $(\mathrm{p}<0.0001)$. The details of the antiviral treatment were presented for 2012 (the beginning of the study) and for 2017 (the end of the study) of the entire observation period. In 2012, GCV monotherapy, sequential therapy and VGCV monotherapy were used in 12 neonates (57\%), 7 neonates (33\%) and 2 neonates (10\%), respectively. In 2012, the mean duration of intravenous GCV therapy was $31 \pm 19$ days (36 \pm 7 days for GCV monotherapy, $21 \pm 10$ days for sequential therapy). The mean length of hospitalization depended on the type of antiviral therapy; it was $38 \pm 8$ days for GCV monotherapy, $28 \pm 9$ days for sequential therapy and $6 \pm 1$ days for oral VGCV monotherapy. By contrast in 2017, GCV was not used as monotherapy in any case; 29 neonates (83\%) were treated with oral VGCV monotherapy, while 6 neonates (17\%) underwent sequential therapy. In 2017, when sequential treatment was applied during the $1^{\text {st }}$ hospitalization, the mean duration of GCV administration was $21 \pm 9$ days. Then, VCGV was used for $9 \pm 6$ days, until the day of discharge from the hospital, and then continued at home. The mean length of hospitalization was associated with the type of antiviral therapy; it was $29 \pm 13$ days for sequential therapy and $9 \pm 4$ day for VGCV monotherapy.

During antiviral treatment, we measured the viral load in blood and urine at every visit. At baseline, before drug administration, viremia and viruria were comparable in both groups $(\mathrm{p}>0.05)$ (Table 1$)$. At the follow-up visit, the HCMV DNA concentration in blood was significantly lower in group 2 than in group $1(\mathrm{p}=0.04)$ (Table 2). Positive results of PCR for HCMV DNA in CSF were observed in $16.8 \%$ of the study population (20\% in group 1 and $11 \%$ in group 2) at baseline (Fig. 1), but in only $3 \%$ of the infants in both groups at follow-up (Table 2).

At baseline, the prevalence of neutropenia $(<1000 \mathrm{G} / \mathrm{L})$ was $18 \%$ in the entire cohort. There were no statistical differences in neutrophil counts between the 2 study groups (Table 1). At the follow-up hospitalization, the prevalence of neutropenia was $24 \%$ in the entire cohort. There were no statistically significant differences in neutrophil counts and the prevalence of neutropenia between the study groups during the $2^{\text {nd }}$ hospitalization (Table 2). However, severe neutropenia (grade 4: $<500$ neutrophils G/L) was observed, mainly in group 1 (5 cases), with the lowest count of 153 neutrophils G/L, while in group 2 neutropenia was noted in 1 patient with the lowest count of 459 neutrophils G/L.

As far as clinical characteristics were concerned, we observed the following abnormalities during the baseline visit: intra/paraventricular cysts (74.4\%), vasculopathy

Table 1. Baseline characteristics of symptomatic newborn infants with cCMV and comparisons of the study groups in relation to the treatment regimen

\begin{tabular}{|c|c|c|c|c|}
\hline Characteristics & $\begin{array}{l}\text { Study population } \\
\qquad n=98\end{array}$ & $\begin{array}{c}\text { Group } 1 \\
\text { GCV only or GCV + VGCV } \\
n=60\end{array}$ & $\begin{array}{l}\text { Group } 2 \\
\text { VGCV } \\
n=38\end{array}$ & $p$-value \\
\hline Birth weight [g] & $2535 \pm 690$ & $2395 \pm 665$ & $2756 \pm 680$ & $0.011^{\mathrm{a}}$ \\
\hline Gestational age [weeks] & $37 \pm 3$ & $37 \pm 3$ & $38 \pm 2$ & NS \\
\hline Head circumference [cm] & $33 \pm 3$ & $32 \pm 2.9$ & $34 \pm 2.2$ & $0.002^{\mathrm{a}}$ \\
\hline Age at admission to NICU [days] & $15 \pm 13$ & $13 \pm 13$ & $17 \pm 12$ & NS \\
\hline Thrombocytes [G/L] & $163 \pm 122$ & $118 \pm 95$ & $234 \pm 128$ & $<0.001^{\mathrm{a}}$ \\
\hline Neutrophils [G/L] & $1987 \pm 1398$ & $1871 \pm 1511$ & $2171 \pm 1195$ & NS \\
\hline ASPAT [U/L] & $71 \pm 117$ & $91 \pm 145$ & $38 \pm 13$ & $0.033^{\mathrm{a}}$ \\
\hline ALAT [U/L] & $33 \pm 50$ & $40 \pm 62$ & $21 \pm 10$ & NS \\
\hline $\begin{array}{l}\text { Blood viral load } \\
\text { [number of viral copies/mL] }\end{array}$ & - & $\begin{array}{l}339 \times 10^{3} \\
\pm 830 \times 10^{3}\end{array}$ & $\begin{array}{c}104 \times 10^{3} \\
\pm 190 \times 10^{3}\end{array}$ & NS \\
\hline $\begin{array}{l}\text { Urine viral load } \\
\text { [number of viral copies/mL] }\end{array}$ & - & $\begin{array}{c}5830 \times 10^{3} \\
\pm 4517 \times 10^{3}\end{array}$ & $\begin{array}{c}7520 \times 10^{3} \\
\pm 3960 \times 10^{3}\end{array}$ & NS \\
\hline
\end{tabular}

Data is presented as mean \pm SD; NS - not significant ( $p$-value above 0.05); cCMV - congenital cytomegalovirus infection; GCV - ganciclovir; VGCV - valganciclovir; $\mathrm{NICU}$ - neonatal intensive care unit; ASPAT - aspartate transaminase; ALAT - alanine aminotransferase; ${ }^{\mathrm{a}} \mathrm{p}$-values below 0.05 are statistically significant. 
Table 2. Comparison of follow-up characteristics of symptomatic infants with cCMV in relation to the treatment regimen

\begin{tabular}{|c|c|c|c|}
\hline Characteristics & $\begin{array}{c}\text { Group } 1 \\
\text { GCV only or GCV+VGCV } \\
n=60, n(\%)\end{array}$ & $\begin{array}{c}\text { Group } 2 \\
\text { VGCV } \\
\mathrm{n}=38, \mathrm{n}(\%)\end{array}$ & $\mathrm{p}$-value \\
\hline Age [days] & $77 \pm 26$ & $55 \pm 17$ & $<0.001^{\mathrm{a}}$ \\
\hline Weight [g] & $4519 \pm 1042$ & $4170 \pm 1118$ & NS \\
\hline Head circumference $[\mathrm{cm}]$ & $37 \pm 3$ & $39 \pm 12$ & NS \\
\hline Thrombocytopenia, n (\%) & $1(2)$ & $0(0)$ & NS \\
\hline Thrombocytes [G/L] & $376 \pm 137$ & $478 \pm 134$ & $0.001^{\mathrm{a}}$ \\
\hline Neutropenia $[<1000 \mathrm{G} / \mathrm{L}]$ & $15(25)$ & $10(26)$ & NS \\
\hline Neutrophils [G/L] & $1866 \pm 1501$ & $1822 \pm 1098$ & NS \\
\hline Splenomegaly, n (\%) & $8(13)$ & $1(3)$ & NS \\
\hline Cholestasis, n (\%) & $5(8)$ & $0(0)$ & NS \\
\hline ASPAT [U/L] & $45 \pm 38$ & $44 \pm 31$ & NS \\
\hline ALAT [U/L] & $36 \pm 30$ & $36 \pm 33$ & NS \\
\hline Vasculopathy at US, n (\%) & $16(27)$ & $12(32)$ & NS \\
\hline Peri/intraventricular cysts at US, n (\%) & $21(35)$ & $12(32)$ & NS \\
\hline Positive PCR CMV in CSF, n (\%) & $2(3)$ & $1(3)$ & NS \\
\hline Ophtalmologic abnormalities, n (\%) & $13(22)$ & $3(8)$ & NS \\
\hline Blood viral load [number of viral copies/mL] & $72 \times 10^{3} \pm 432 \times 10^{3}$ & $1 \times 10^{3} \pm 2 \times 10^{3}$ & $0.044^{\mathrm{a}}$ \\
\hline Urine viral load [number of viral copies/mL] & $132 \times 10^{3} \pm 510 \times 10^{3}$ & $680 \times 10^{3} \pm 235 \times 10^{3}$ & NS \\
\hline
\end{tabular}

Data is presented as numbers (\%) or mean \pm SD; NS - not significant; CCMV - congenital cytomegalovirus infection; GCV - ganciclovir; VGCV - valganciclovir; ASPAT - aspartate transaminase; ALAT - alanine aminotransferase; US - ultrasonography; CSF - cerebrospinal fluid; ${ }^{2}$ p-values below 0.05 are statistically significant.

= group 1 (GCV only or GCV + VGCV) $\quad$ group $2(V G C V)$

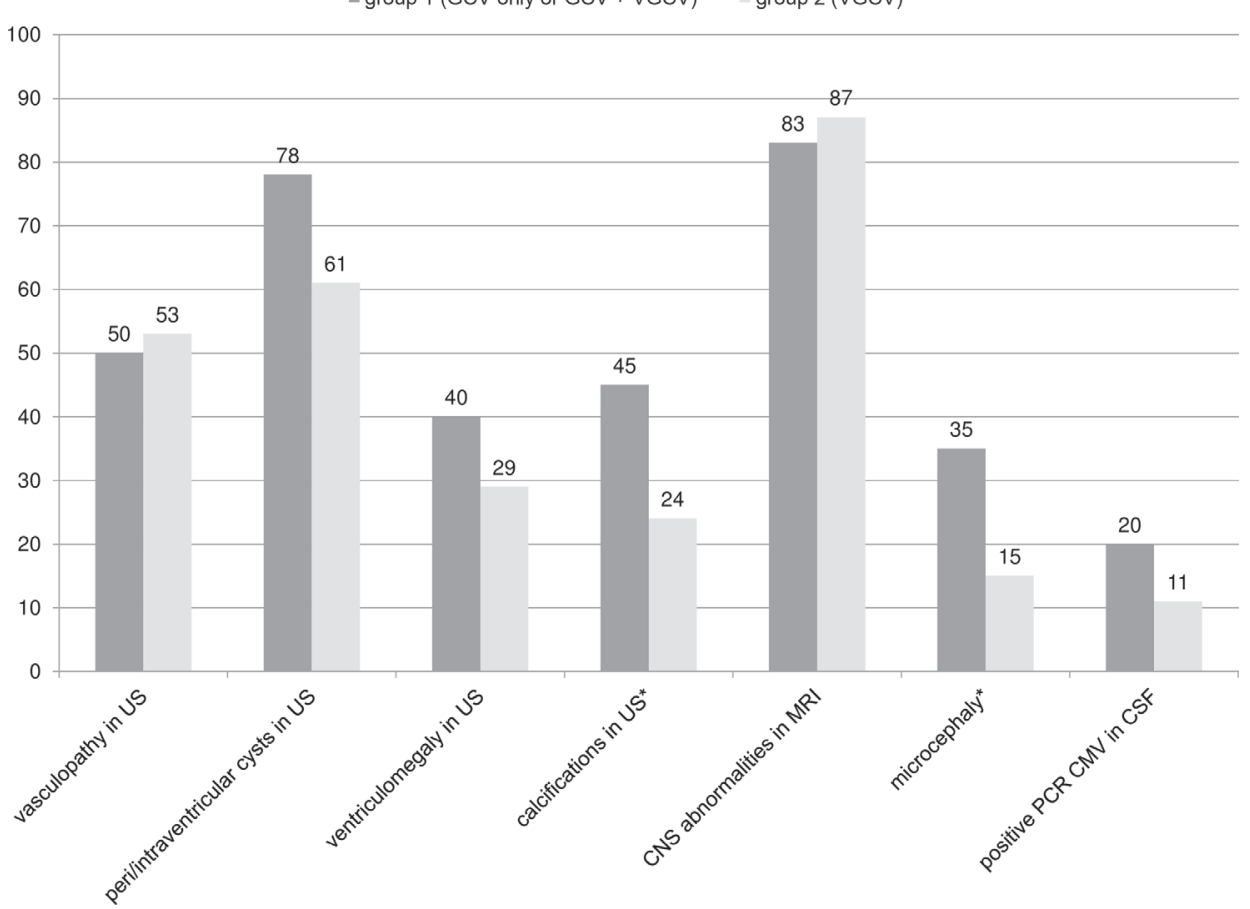

Fig. 1. Comparison of baseline CNS involvement between the GCV group (GCV or GCV + VGCV) and the VGCV group. *For statistically significant differences, $\mathrm{p}$-values $<0.05$ are shown
(52\%), abnormal OAE in at least 1 ear in 45 children among 96 with available results (46.8\%), thrombocytopenia (43.9\%), ventriculomegaly (37.7\%), intracranial calcifications (36.7\%), ophthalmologic abnormalities (34.6\%), splenomegaly (27.5\%), neutropenia (22.4\%), cholestasis (22.4\%), petechiae (21.4\%), and positive PCR HCMV DNA in CSF (16.3\%). The neonates in group 1 had a significantly higher prevalence of petechiae, splenomegaly, cholestasis, thrombocytopenia, elevated liver enzymes, intracranial calcifications in US, lower birth weights, and lower head circumferences (Table 1, Fig. 1,2). At the follow-up visit, the results of physical examination, laboratory blood tests 


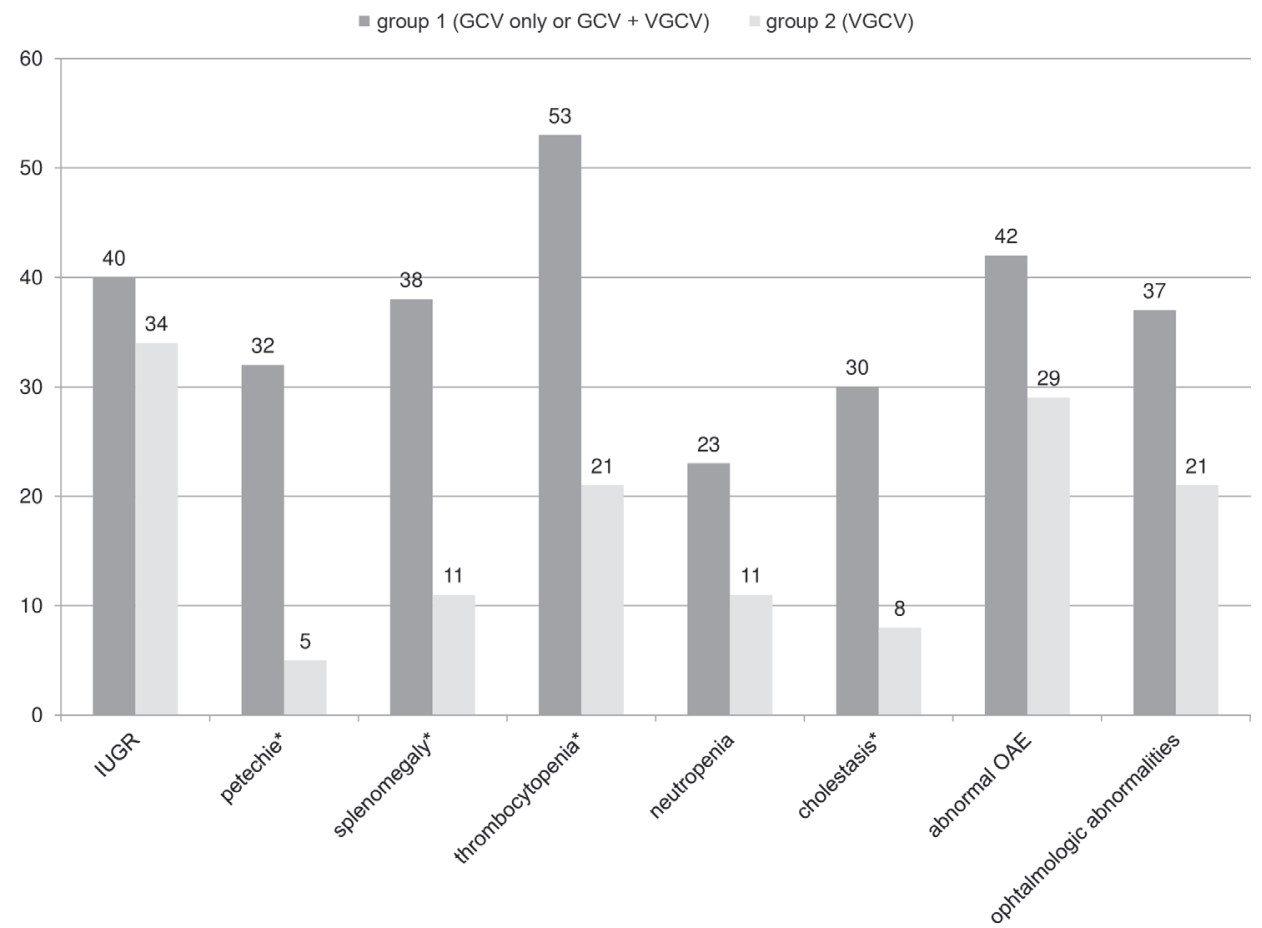

Fig. 2. Comparison of baseline characteristics between the GCV group (GCV or GCV + VGCV) and the VGCV group. *For statistically significant differences, $\mathrm{p}$-values $<0.05$ are shown and neuroimaging were not significantly different between the 2 study groups, except for a significantly lower mean platelet count in group 1 . However, thrombocytopenia was found in only 1 patient in this group (Table 2 ).

The baseline serological status showed that the 96 (100\%) newborns with results available had positive CMV-IgG (in 2 cases the results were not available). Only 48 of 96 patients (50\%) had positive CMV-IgM and 5 of 96 patients (5.2\%) had grey-zone CMV-IgM.

\section{Discussion}

We compared 2 treatment methods in a cohort of neonates in Poland with symptomatic cCMV: GCV-based therapy (intravenous GCV or sequential GCV + VGCV therapy) compared to oral VGCV monotherapy. Initially, on the basis of international recommendations, ${ }^{12} 6$ weeks of intravenous GCV therapy for cCMV were recommended in Poland. When the oral suspension of VGCV was available in Europe, we introduced oral therapy for cCMV, with a final extension to 6 months, as the first-choice of treatment for $\mathrm{CCMV}$, in accord with international and European recommendations..$^{9-11,13,14,16,17}$

As expected, we noted that between 2012 and 2017, the percentage of neonates with cCMV on oral VGCV increased from $43 \%$ to $100 \%$, while those on intravenous GCV as a monotherapy decreased from $57 \%$ to $0 \%$. Similarly, the proportion of infants with cCMV in the USA who had VGCV treatment increased significantly between 2009 and $2015 .^{5}$

The average duration of intravenous treatment was about 5 weeks for infants on GCV monotherapy. If sequential therapy was applied, intravenous treatment was reduced to about 3 weeks. In our center, we tended to switch to oral therapy as soon as the clinical status and laboratory results improved and the oral drug could be administered. Our study showed that among infants on VGCV monotherapy, the length of hospitalization was over 6 times shorter than for infants on GCV monotherapy. The growing number of infants with cCMV on oral VGCV treatment led to the time of hospitalization becoming over 2.5 times shorter during the six-year observation period.

Oral treatment methods also entail other benefits, such as decreased risk of nosocomial infections, diminished stress for parents and infants, and lower economic costs. ${ }^{18}$ Additionally, oral therapy avoids the complications of intravenous injections. In Poland, neonates have to stay in the hospital for the duration of intravenous therapy through peripheral intravenous catheters or peripherally inserted central catheters (PICCs). In a study by Amir et al., infants received GCV through a central venous catheter (usually a PICC line), which allowed for home treatment and eliminated the risks of prolonged hospitalization. However, 2 patients experienced central line infections. ${ }^{19}$ In our study, we did not analyze the frequency of catheter infections.

Antiviral treatment eliminates HCMV from blood, urine and CSF. ${ }^{13}$ Although recent research shows that the viral load in blood has no clinically meaningful predictive value for long-term outcomes, it was earlier observed that asymptomatic infants with a reduced viral load in the blood and urine were at a lower risk for hearing loss in the future. ${ }^{20,21}$ We showed a 70 times lower viral load in the blood in the VGCV-based group than in the GCV-based group during the $1^{\text {st }}$ follow-up visit. It is widely known that viruria and viremia can recur about 
2 weeks after discontinuation of antiviral therapy. Thus, the rebound-effect after completing intravenous treatment might explain the higher viral load in the blood and urine in the GCV-based-group at the follow-up visit. It should be emphasized that HCMV can be excreted in the urine for up to $2-5$ years after infection. ${ }^{13,22,23}$ We detected HCMV DNA in CSF in only $16.8 \%$ of the cases, although over $80 \%$ of the infants had abnormal neuroimaging. The detection of HCMV DNA in CSF using PCR was not a sensitive marker of $\mathrm{CCMV}$ neuroinfection in the current study. Interestingly, Lisowska-Mikołajków et al. suggested expanding the assessment of other newborn fluids such as blood and CSF if the number of HCMV copies in urine exceed 500 copies $/ \mathrm{mL}$. In other situations, high numbers of HCMV copies in blood or CSF are unlikely. ${ }^{18}$

Myelosuppression, especially neutropenia, was the main side effect of GCV/VGCV treatment in our study. It was the main reason for discontinuing intravenous therapy. Temporal cessation of oral therapy was also necessary in cases of severe neutropenia. When grade 4 neutropenia occurred during treatment, we usually stopped antiviral therapy and administered recombinant human granulocyte colony-stimulating factor (rhG-CSF) until the patient's blood tests results improved. Ronchi et al. presented serious consequences of neutropenia for infants, including bacterial sepsis. ${ }^{24}$ Fortunately, we did not observe any severe bacterial sepsis or death due to neutropenia during antiviral therapy. In previous studies, grade 3 or 4 neutropenia was reported in $63 \%$ of infants with cCMV during six-week GCV treatment, but in only $21 \%$ of infants during six-month VGCV-treatment and in $27 \%$ of infants in a placebo group. ${ }^{11,12,25}$ Thus, the problem was more pronounced in GCV therapy. ${ }^{5}$ In our study, however, there were no statistically significant differences between the 2 study groups in terms of percentages of neutropenia and mean levels of neutrophils at the follow-up visits.

Undoubtedly, newborn infants with severe disseminated disease ("septicemic") and those who are unable to absorb medications from the gastrointestinal tract (including preterm infants) benefit from intravenous GCV therapy until a stabilization of their general condition and the safe introduction of oral treatment. ${ }^{14}$ In our study, newborns on GCV therapy more often demonstrated petechiae, splenomegaly, cholestasis, thrombocytopenia, calcifications in CNS, as well as lower birth weights and head circumferences, and they were usually born prematurely.

We also investigated baseline serological status of the study population. It is obvious that all CCMV-infected newborns had positive CMV-IgG, due to transplacental transfer, as opposed to CMV-IgM, which was produced by the fetus itself. Positive CMV-IgM was found in only $50 \%$ of the entire cohort of symptomatic newborns. Interestingly, Ohyama et al. observed positive CMV-IgM in 25/32 of symptomatic infants with cCMV infection (78\%). ${ }^{26}$ Undoubtedly, negative CMV-IgM did not exclude
cCMV infection and assessment of neonatal serological status is not a reliable tool for a diagnosis of $\mathrm{CCMV}^{18,26}$

Unfortunately, the available data limited our observation period in the current study to 1 follow-up visit about 4-6 weeks after the $1^{\text {st }}$ hospitalization, so we could not analyze long-term outcomes. Kimberlin et al. observed that 6 months of VGCV administration led to improved hearing or protection of normal hearing at 12 months and at 24 months. Similarly, patients with CNS abnormalities also had better outcomes from baseline to 12 months and 24 months. ${ }^{11}$ By contrast, Fukushima et al. observed that infants with microcephaly and those who were small for their gestational age (SGA) at birth presented severe sequelae and development quotients $<70$ at around 18 months of age, despite 6 weeks to 6 months of VGCV treatment. ${ }^{27}$ Undoubtedly, further investigations with long observation periods are needed to evaluate neurodevelopmental outcomes among orally treated cCMV-infected patients.

Another limitation of our study was incomplete data of GCV level due to the retrospective character of the study. Moreover, the low number of infants on exclusive intravenous therapy did not allow us to separate these infants and create a $3^{\text {rd }}$ group for comparison. Finally, hearing evaluation was based on OAE, because data on auditory brainstem responses (ABR) were not available for all the participants.

The strength of the study is the relatively large and homogenous population consisting of 98 symptomatic newborns with confirmed cCMV. To the best of our knowledge, our cohort of Polish newborns with symptomatic cCMV is one of the biggest cohorts that has been described to date.

\section{Conclusions}

In summary, VGCV became the first line of antiviral therapy in cCMV in the study population. Compared to GCV-based treatment, VGCV monotherapy allowed shorter hospital stays and reduced the viral load in blood due to the treatment being continued at home. Moreover, severe neutropenia was less frequent in VGCV monotherapy than in GCV-based treatment. However, intravenous GCV is still suitable for patients with severe disseminated disease, born prematurely, with low birth weights, or not tolerating enteral feeding. In those infants, sequential GCV + VGCV therapy seems to be optimal.

\section{ORCID iDs}

Dominika Jedlińska-Pijanowska (1) https://orcid.org/0000-0002-0173-1150 Justyna Czech-Kowalska (D) https://orcid.org/0000-0001-7563-3951 Magdalena Kłodzińska (D) https://orcid.org/0000-0003-1535-1332 Aleksandra Pietrzyk (D) https://orcid.org/0000-0003-0519-2278 Eliza Michalska (1) https://orcid.org/0000-0001-7381-3254

Kinga Gradowska (D) https://orcid.org/0000-0002-0913-8116 Anna Dobrzańska (D) https://orcid.org/0000-0003-2927-2344 Beata Kasztelewicz (D) https://orcid.org/0000-0003-1504-5589 Dariusz Gruszfeld (D) https://orcid.org/0000-0002-2414-4928 


\section{References}

1. Gelemanovic A, Dobberpuhl K, Krakar G, Patarčić I, Kolčić I, Polašek O. Host genetics and susceptibility to congenital and childhood cytomegalovirus infection: A systematic review. Croat Med J. 2016;57(4): 321-330.

2. Marsico C, Kimberlin DW. Congenital cytomegalovirus infection: Advances and challenges in diagnosis, prevention and treatment. Ital J Pediatr. 2017;43(1):38.

3. Khalil A, Heath P, Jones C, Soe A, Ville YG; on behalf of the Royal College of Obstetricians and Gynaecologists. Congenital cytomegalovirus infection: Update on treatment. BJOG. 2018;56:e1-e11.

4. Plosa EJ, Esbenshade JC, Fuller MP, Weitkamp JH. Cytomegalovirus infection. Pediatr Rev. 2012;33(4):156-163.

5. Leung J, Dollard SC, Grosse SD, et al. Valganciclovir use among commercially and Medicaid-insured infants with congenital CMV infection in the United States, 2009-2015. Clin Ther. 2018;40(3):430-439.e431.

6. Bartlett AW, Hall BM, Palasanthiran P, McMullan B, Shand AW, Rawlinson WD. Recognition, treatment, and sequelae of congenital cytomegalovirus in Australia: An observational study. J Clin Virol. 2018:108:121-125.

7. Dietrich $\mathrm{ML}$, Schieffelin JS. Congenital cytomegalovirus infection. Ochsner J. 2019;19(2):123-130.

8. Zhang XY, Fang F. Congenital human cytomegalovirus infection and neurologic diseases in newborns. Chin Med J (Engl). 2019;132(17): 2109-2118.

9. Rawlinson WD, Boppana SB, Fowler KB, et al. Congenital cytomegalovirus infection in pregnancy and the neonate: Consensus recommendations for prevention, diagnosis, and therapy. Lancet Infect Dis. 2017;17(6):e177-e188.

10. LuckSE, Wieringa JW, Blazquez-Gamero D, et al; ESPID Congenital CMV Group Meeting, Leipzig 2015. Congenital cytomegalovirus: A European Expert Consensus Statement on Diagnosis and Management. Pediatr Infect Dis J. 2017;36(12):1205-1213.

11. Kimberlin DW, Jester PM, Sanchez PJ, et al; National Institute of Allergy and Infectious Diseases Collaborative Antiviral Study Group. Valganciclovir for symptomatic congenital cytomegalovirus disease. N Engl J Med. 2015;372(10):933-943.

12. Kimberlin DW, Lin CY, Sanchez PJ, et al; National Institute of Allergy and Infectious Diseases Collaborative Antiviral Study Group. Effect of ganciclovir therapy on hearing in symptomatic congenital cytomegalovirus disease involving the central nervous system: A randomized, controlled trial. J Pediatr. 2003;143(1):16-25.

13. Kimberlin DW, Acosta EP, Sanchez PJ, et al; National Institute of Allergy and Infectious Diseases Collaborative Antiviral Study Group. Pharmacokinetic and pharmacodynamic assessment of oral valganciclovir in the treatment of symptomatic congenital cytomegalovirus disease. J Infect Dis. 2008;197(6):836-845.
14. Kimberlin DB, Brady MT, Jackson MA, Long SS, eds. Red Book: 2015 Report of the Committee on Infectious Diseases. Elk Grove Village, IL: American Academy of Pediatrics; 2015:317-322.

15. Kasztelewicz B, Czech-Kowalska J, Lipka B, et al. Cytokine gene polymorphism associations with congenital cytomegalovirus infection and sensorineural hearing loss. Eur J Clin Microbiol Infect Dis. 2017; 36(10):1811-1818.

16. Kadambari S, Williams EJ, Luck S, Griffiths PD, Sharland M. Evidencebased management guidelines for the detection and treatment of congenital CMV. Early Hum Dev. 2011;87(11):723-728.

17. Niezgoda A, Czech-Kowalska J, Piłat K, et al. Congenital CMV infection: Guidelines. Stand Med Ped. 2018;2:172-177.

18. Lisowska-Mikołajków D. Mikołajków A, Reczuch J. Królak-Olejnik B. Congenital cytomegalovirus infection: Still a relevant problem (based on own experience and literature) [in Polish]. Dev Period Med. 2018; 22(1):49-57.

19. Amir J, Wolf DG, Levy I. Treatment of symptomatic congenital cytomegalovirus infection with intravenous ganciclovir followed by longterm oral valganciclovir. Eur J Pediatr. 2010;169(9):1061-1067.

20. Marsico C, Aban I, Kuo H, et al; Collaborative Antiviral Study Group (CASG). Blood viral load in symptomatic congenital cytomegalovirus infection. J Infect Dis. 2019;219(9):1398-1406.

21. Boppana SB, Fowler KB, Pass RF, etal. Congenital cytomegalovirus infection: Association between virus burden in infancy and hearing loss. J Pediatr. 2005;146(6):817-823.

22. Whitley RJ, Cloud G, Gruber W, et al; National Institute of Allergy and Infectious Diseases Collaborative Antiviral Study Group. Ganciclovir treatment of symptomatic congenital cytomegalovirus infection: Results of a phase II study. J Infect Dis. 1997;175(5):1080-1086.

23. Tanaka-Kitajima N, Sugaya N, Futatani T, et al. Ganciclovir therapy for congenital cytomegalovirus infection in six infants. Pediatr Infect Dis J. 2005;24(9):782-785.

24. Ronchi A, Pietrasanta C, Binda S, Mosca F, Pugni L. Congenital cytomegalovirus infection and antiviral therapy: How to manage neutropenia properly? Pediatr Infect Dis J. 2019;38(8):e190.

25. Ziv L, Yacobovich J, Pardo J, et al. Hematologic adverse events associated with prolonged valganciclovir treatment in congenital cytomegalovirus infection. Pediatr Infect Dis J. 2019;38(2):127-130

26. Ohyama S, Fujioka K, Fukushima S, et al. Diagnostic value of cytomegalovirus IgM antibodies at birth in PCR-confirmed congenital cytomegalovirus infection. Int J Mol Sci. 2019;20(13):3239.

27. Fukushima S, Morioka I, Ohyama S, et al. Prediction of poor neurological development in patients with symptomatic congenital cytomegalovirus diseases after oral valganciclovir treatment. Brain Dev. 2019;41(9):743-750. 